\title{
The impact of bitter taste receptor genetics on culturable bacteria in chronic rhinosinusitis*
}

\author{
Darren I. Rom', Jenna M. Christensen', Raquel Alvarado', \\ Raymond Sacks ${ }^{2,3}$, Richard J. Harvey ${ }^{1,2}$ \\ ' Rhinology and Skull Base Research Group, St Vincent's Centre for Applied Medical Research, University of New South Wales, \\ Sydney, NSW, Australia \\ 2 Faculty of Medicine and Health Sciences, Macquarie University, Sydney, NSW, Australia \\ ${ }^{3}$ Faculty of Medicine, University of Sydney, Sydney, NSW, Australia
}

Rhinology 55: 90-94, 2017

https://doi.org/10.4193/Rhino16.181

*Received for publication:

May 29, 2016

Accepted: November 27, 2016

\begin{abstract}
Background: Extra-oral bitter taste receptors have been associated with innate bacterial defence mechanisms. Genetic variation in T2R38 functionality has been shown to be associated with susceptibility to upper respiratory tract infections and chronic rhinosinusitis (CRS). We sought to independently assess the influence of bitter taste receptor genotype on the presence of culturable bacteria in the sinuses.
\end{abstract}

Methodology: A cross-sectional analysis of patients with CRS undergoing surgery was performed. Middle meatal nasal swabs were sent for microbiological evaluation at the time of the procedure. Mucosal biopsies were taken and sent for bitter taste receptor genotype analysis. Sequencing of 3 polymorphisms in the TAS2R38 gene was performed to identify genotypes as supertasters (PAV/PAV), non-tasters (AVI/AVI) or heterozygous expression (PAV/AVI). The presence of culturable organisms and common pathogens were compared with bitter taste receptor genotypes.

Results: 25 patients (age $52.4 \pm 18.28$ years, $51 \%$ female) were assessed. Super-tasters comprised $16 \%$ of the group, $24 \%$ were non-tasters and $48 \%$ had heterozygous expression. A cultured pathogen was grown in $48 \%$ of patients; $32 \%$ gram-positive, $20 \%$ gram-negative, 28\% grew Staphylococcus aureus and 12\% Pseudomonas aeruginosa. A non-taster genotype was predictive of colonised pathogens. Tissue eosinophilia (>10/HPF) was seen in $48 \%$.

Conclusion: Even in a small sample of patients with CRS, non-taster T2R38 genotype appears to predict the presence of culturable bacteria colonising the sinus cavity at the time of surgery for their condition. A genetic link to patients more likely to become 'infected' is likely.

Key words: chronic rhinosinusitis, bitter taste receptor, genotype, culture, pathogen

\section{Introduction}

Chronic rhinosinusitis (CRS) is a heterogeneous disorder involving a number of complex pathological and immunological processes ${ }^{(1)}$. The growing advances in the genetics has played a key role in gaining understanding of these complex mechanisms, and provides the opportunity for identifying new drug targets for treatment that have otherwise not been explored. In particular, the role of extra-oral bitter taste receptors, specifically the T2R38 isoform, and its association with innate bacterial defence mechanisms, including the activation of nitric oxide-dependent responses in sinonasal cilia by gram-negative quorum-sensing molecules called acyl-homoserine lactones (AHLs) ${ }^{(2-5)}$. Polymorphisms within the T2R38 gene, TAS2R38, confer variability in immune protective mechanisms by rendering the receptor inactive (unresponsive to AHLs). Furthermore, it has been suggested that individuals with homogeneity for the non-functional allele (AVI/AVI) or 'non-tasters' appear to be less protected from gramnegative upper respiratory tract infections and predisposed to recalcitrant CRS compared with individuals with at least one functional allele (PAV/AVI) or two functional alleles (PAV/PAV) or 
'super-tasters' (6,7). An initial study conducted by Lee et al. (2012) linked super-tasters with lower frequency of gram-negative sinonasal infections, postulating that that these individuals have a more efficient bacterial killing response ${ }^{(8)}$. There is a high level of genetic variability within the population and although studies have demonstrated an association of the AVI allele with CRS, it remains to be shown whether the AVI allele and microbial colonisation directly contributes to CRS development. The objective of this study was to independently assess the influence of bitter taste genotype on the pattern of planktonic bacteria cultures obtained from the paranasal sinuses in patients with CRS.

\section{Materials and methods}

\section{Study design}

A cross-sectional analysis of CRS patients undergoing sinus surgery was performed. Data including microbiology and histopathology were collected at the time of surgery. Mucosal biopsies were sent for genotype sequencing. Approval from the St Vincent's Human Research Ethics Committee was obtained (SVH 09/08 and HREC/10/SVH/117).

\section{Patient population}

Patients ( $>18$ years) with CRS with or without polyps (CRSwNP and CRSsNP, respectively) who underwent endoscopic sinus surgery (ESS) in a tertiary referral clinic were included. CRS patients were defined based on the European Position Paper on Rhinosinusitis and Nasal Polyps (EP3OS) ${ }^{(1)}$. Patients received maximum medical therapy prior to surgery, which included a 3 week course of oral prednisone (1 week each of $25 \mathrm{mg} /$ day, 12.5 $\mathrm{mg} /$ day, and $5 \mathrm{mg} /$ day), topical steroid spray or irrigation, and saline irrigation. Additionally, a 20-day course of amoxicillin/ clavulanic acid was given when discolored discharge from the middle meatus was observed, and altered if indicated by culture from subsequent endoscopically-guided meatal swabs. Patients were followed up at 4 to 6 weeks to assess response to medical therapy ${ }^{(9)}$. No patients received oral steroids or antibiotics for 4 weeks prior to surgery. Demographic data was recorded and informed consent was obtained from all patients prior to surgery.

\section{Genotype sequencing}

Mucosal tissue was biopsied from the maxillary or ethmoid sinus during surgery and placed in RNAlater. Patients were genotyped using the mucosa obtained during surgery as previously described ${ }^{(6,8,10)}$. These samples were preserved in RNAlater at the time of tissue acquisition. Genomic DNA was extracted from specimens following the directions of the manufacturer (QIAmp DNA Mini kit and Blood Mini kit; Qiagen). Following extraction, samples were quantified by a spectrophotometer (ND-1000; Nanodrop), using $1.5 \mu$ l of extracted genomic DNA. Samples were diluted to $5 \mathrm{ng} / \mu \mathrm{l}$ and genotyped using the $A B I$ StepOne real-time PCR system. Alleles of the TAS2R38 gene were geno- typed for a variant site using allele-specific probes and primers (Applied Biosystems). Patients were categorised as super-tasters (PAV/PAV), non-tasters (AVI/AVI) or showing heterozygous expression (PAV/AVI). The genotype sequencing was performed by researchers blinded to the microbiology outcomes.

\section{Histopathologic assessment for eosinophilia}

Sinus mucosal tissue was biopsied from the maxillary or ethmoid sinus during surgery. Specimens were fixed in $10 \%$ buffered formalin and embedded in paraffin wax. Blocked specimens were sectioned at $3 \mu \mathrm{m}$ and mounted on standard glass slides for haematoxylin-eosin (HE) staining. A previously reported histopathologic scoring system was used ${ }^{(11)}$. Eosinophilic CRS (eCRS) was defined as $>10$ eosinophils/HPF (high power field). The eosinophil category from $\mathrm{HE}$ was derived from the 3 densest collections of eosinophils in the stroma. Patients were classified as $>10 /$ HPF if 2 or more areas had $>10 /$ HPF eosinophil density.

\section{Microbiology}

Sampling of sinus secretions was performed prior to surgery with an endoscopically directed swab (Transwab ${ }^{\circledR}$ E.N.T for Aerobes and Anaerobes, ENT Amies Plain, Sigma-Aldrich, St. Louis, MO, USA) of each middle meatus as this was thought to offer the best chance of a non-contaminated sample ${ }^{(12)}$. Each swab was subject to microscopy, culture and sensitivity $(M C+S)$. A routine gram-stain was performed and the presence of polymorphs and bacteria was quantified and reported. All middle meatal sinus swabs were inoculated on to Blood agar for general bacterial growth, Chocolate agar for fastidious organisms, and MacConkey agar for lactose fermenting gram-negative rods. All plates were incubated at $35^{\circ} \mathrm{C}$ in carbon dioxide and examined for significant growth for 2 days. Chromogenic yeast agar was incubated for an additional 5 days to allow for the growth of slow growing yeast and fungus. In addition, an anaerobic agar plate was inoculated and incubated in an anaerobic atmosphere and examined after $48 \mathrm{hrs}$. Fungal microscopy was prepared using a $15 \%$ potassium hydroxide and $0.1 \%$ calcofluor white (CFW) preparation and preserved at $4{ }^{\circ} \mathrm{C}$ in a humid chamber. An epifluorescence microscope equipped with a mercury vapour lamp detected fungal stains as either bright green or blue-white, depending on the filter used. Full identification was performed for the following pathogens: Pseudomonas spp., gram negative rods, Beta haemolytic streptococci, Staphylococcus aureus, Haemophilus influenzae, Streptococcus pneumoniae, Moraxella, Klebsiella, yeast and Aspergillus spp. The analysis of microbiology was assessed at the time of surgery using the following components: presence of polymononuclear (PMN) cells (absent, present); presence of a culturable pathogen (absent, present); gram-positive organisms (absent, present); gram-negative organisms (absent, present); presence of specific pathogens including Staphylococcus aureus (absent, present) and Pseudomonas (absent, present). 
Table 1. Baseline clinical, genotypic, and histopathological scores.

\begin{tabular}{|c|c|c|c|c|}
\hline & $\begin{array}{l}\text { Super-taster } \\
\text { (PAV/PAV) }\end{array}$ & $\begin{array}{c}\text { Genotype } \\
\text { Heterozygotes } \\
\text { (PAV/AVI) }\end{array}$ & Non-taster (AVI/AVI) & P value \\
\hline Patient number $\%(n=25)$ & $16 \%(4)$ & $\begin{array}{l}\text { AVI/PAV: } 49 \%(12) \\
\text { AAV/AVI: } 8 \%(2) \\
\text { AAV/PAV: } 4 \%(1)\end{array}$ & $24 \%(6)$ & \\
\hline Mean age & $37.7 \pm 15.83$ & $59.0 \pm 17.50$ & $48.6 \pm 21.14$ & $P=0.094$ \\
\hline Gender (\% female) & $16 \%$ & $60 \%$ & $24 \%$ & $p=0.885$ \\
\hline CRSwNP (\%) & $27 \%$ & $63 \%$ & $10 \%$ & $p=0.297$ \\
\hline eCRS & $17 \%$ & $58 \%$ & $25 \%$ & $p=0.935$ \\
\hline
\end{tabular}

\section{Statistical analysis}

Statistical analyses were performed using SPSS v 23 (IBM Statistical Package for the Social Sciences, Chicago, IL, USA). Parametric data was expressed as mean with standard deviation, and nonparametric as median with interquartile range (IQR). Pearson correlation coefficients were performed for linear relationships of scale variables. Proportions were analysed using the Chi squared function for nominal variables. Fisher's exact tests were used for outcomes with less than 5 values across two or more variables. Mann-Whitney U Tests (two-tailed) were used to compare non-parametric data. Results were deemed significant with a p-value of $<0.05$. Heterozygous expression was defined as PAV/ AVI. Additional groupings including AAV/AVI and AVI/AVI were excluded from the analysis, but if collapsed into the heterozygous group the findings were similar. The pathology categories were pre-defined and assessed as independent outcomes. There was no further division or post-hoc analysis.

\section{Results}

There were 25 patients (age $52.4 \pm 18.28$ years, $51 \%$ being female) included in the study. A culturable organism was seen in $48 \%(n=12)$ of which gram-positive $32 \%(n=8)$ and gramnegative $20 \%(n=5)$. Common particular species cultured from all specimens were Staphylococcus aureus $28 \%(n=7)$ and Pseudomonas $12 \%(n=3)$. Supertaster genotyping (PAV/PAV) was present in $16 \%(n=4)$, non-tasters (AVI/AVI) $24 \%(n=6)$ and heterozygous expression (PAV/AVI) 48\% $(n=12)$. Diagnosis of CRSwNP was seen in $44 \%(n=11)$, and tissue eosinophilia was present in $48 \%(n=12)$. Other baseline data are summarised in Table 1.

\section{Comparison by genotype}

Genotype predicted the presence of a culturable bacteria at the time of surgery. A pathogen was cultured in $42 \%$ of non-tasters compared to none $(0 \%)$ in the super-tasters (PAV/PAV 0\% vs. PAV/AVI 58\% vs. AVI/AVI 42\%; X2=9.976, $\mathrm{p}=0.019)$. There were no other significant associations between genotype expression and microbiological or histopathological variables (Table 2). Of patients who grew a pathogen, there was a similar distribution of CRSwNP (42\%) and CRSsNP (58\%) phenotypes ( $p=0.821$ ). Similarly, there was a similar distribution of positive cultures in eCRS (58\%) and non-eCRS (33\%) endotypes ( $p=0.219)$.

\section{Discussion}

The findings that emerged from this study indicate that nontasters (AVI/AVI) and heterozygous (PAV/AVI) individuals are predisposed to culturing bacteria from the sinuses, while homozygous super-tasters (PAV/PAV) appear to be protected from bacterial growth. In contrast to super-tasters being protective of gram-negative culture including Pseudomonas aeruginosa in the study conducted by Lee et al. ${ }^{(8)}$, this was not reproducible from our findings. Furthermore, other microbial growth patterns or particular species were not significantly associated with any taste receptor genotyping. The over-representation of non-tasters in the detection of culturable bacteria from routine clinical testing supports the hypothesis that the non-functional

Table 2. Frequencies ( $n$ ) and statistical significance ( $p$-value) of the associations between genotype expression and microbiological, histopathological and clinical outcomes.

\begin{tabular}{lcccc} 
& PAV/PAV & AVI/PAV & AVI/AVI & P value \\
\hline $\begin{array}{l}\text { Pathogen presence } \\
\text { ( } \mathrm{n}=12 / 25)\end{array}$ & $\mathrm{n}=0$ & $\mathrm{n}=7 / 25$ & $\mathrm{n}=5 / 25$ & $\mathbf{p}=\mathbf{0 . 0 1 9}$ \\
$\begin{array}{l}\text { Gram positive } \\
\text { ( } \mathrm{n}=8 / 25)\end{array}$ & $\mathrm{n}=0$ & $\mathrm{n}=5 / 25$ & $\mathrm{n}=3 / 25$ & $\mathrm{p}=0.195$ \\
$\begin{array}{l}\text { Gram negative } \\
\text { ( } \mathrm{n}=5 / 25)\end{array}$ & $\mathrm{n}=0$ & $\mathrm{n}=3 / 25$ & $\mathrm{n}=2 / 25$ & $\mathrm{p}=0.457$ \\
$\begin{array}{l}\text { Staph aureus } \\
\text { ( } \mathrm{n}=7 / 25)\end{array}$ & $\mathrm{n}=0$ & $\mathrm{n}=5 / 25$ & $\mathrm{n}=2 / 25$ & $\mathrm{p}=0.270$ \\
$\begin{array}{l}\text { Pseudomonas } \\
\text { ( } \mathrm{n}=3 / 25)\end{array}$ & $\mathrm{n}=0$ & $\mathrm{n}=2 / 25$ & $\mathrm{n}=1 / 25$ & $\mathrm{p}=0.723$ \\
\hline
\end{tabular}


genotype of TAS2R38 may be an independent risk factor for medically recalcitrant CRS ${ }^{(6-8)}$. The impact of TAS2R38 genotyping on clinical outcomes has already been demonstrated by Addapa et. al. whereby non-polypoid CRS homozygotes for the super-taster genotype had significantly greater improvements in quality of life scores (SNOT-22) at 6 months post functional endoscopic sinus surgery (FESS) ${ }^{(11)}$. Investigation into the impact of other hypothesised associations including bacterial culture on inflammatory subtype was not demonstrated on a similar cohort of patients in a prior study ${ }^{(13)}$, whereas the effect genotype of bacterial growth was in this investigation.

This study included a broad CRS population, and it is important to recognise the limitations of simple cultivating methods, which may not truly represent the entire bacterial community. Ivanchenko et al. demonstrated that anaerobes presented more frequently in the maxillary sinus compared with the middle meatus and such species may player a larger role in the pathogenesis of CRS compared with aerobic organisms ${ }^{(14)}$. Errors in the collection process and recalcitrant growth on selected media may contribute to an under-representation of cultured organisms. A range of $10-45 \%$ of cultured bacteria have been shown to be routinely negative and inferior to culture-independent studies using DNA sequencing such as 16srRNA pyrosequences and nucleic acid detection (15-17). Despite this, the patients in our sample had an inflammatory disease and a $48 \%$ culture rate via endoscopic middle meatal swabs is often not unexpected.

A meta-analysis conducted by Thanasumpun et al. reported a culture rate of $63.7 \%$ in CRS patients, while $47 \%$ of CRS patients from a similar cohort cultured a pathogen ${ }^{(13,18)}$. Furthermore, the cultured bacteria in this study did not represent an acute or invasive infection in any cases and thus deemed colonised rather than infected by the investigators. The small sample number used in this study, especially in the analysis of individual bacterial species was an additional limitation with the study underpowered to detect individual species. It is also important to appreciate that genotyping has its limitations in assessing receptor phenotype and hence functionality. Methods such as phenylthiocarbamide (PTC) testing for the T2R38 receptor showed that in the non-polypoid population, patients who were superior bitter tasters had significantly lower biofilm formation $(p=0.012$ ) compared with the same cohort who were genotyped $(p=0.204)^{(19)}$.

\section{Conclusion}

Even in a small sample of patients with CRS, the non-taster T2R38 genotype appears to predict the presence of culturable bacteria colonising the sinus cavity at the time of surgery for their condition. This study supports the influence of the T2R38 bitter taste receptor on innate immunity and may be an independent risk factor for medically recalcitrant CRS.

\section{Acknowledgement}

The authors wish to acknowledge Corrine J. Mansfield at the Monell Centre for Chemical Senses, Philadelphia for contribution towards T2R38 sequencing. Additionally, we would like to acknowledge the P30 grant support (P30DC011735) for this work.

\section{Authorship contribution}

DIR: Primary author, data collection, data analysis and interpretation, article drafting; JMC: data collection, data interpretation; RA: data interpretation; RS: critical revision and editing of article; $\mathrm{RJH}$ : design of study, critical revision and editing of article.

\section{Conflict of interest}

$\mathrm{RJH}$ has served on an advisory board for BioCSL and serves on the speaker's bureau for Bayer; he is a consultant for Medtronic, Olympus and NeilMed; and has received grant funding from Stallergenes, ENT Technologies and NeilMed Pharmaceuticals. RS is a consultant with Medtronic. All other authors have no conflicts of interest to declare.

\section{References}

1. Fokkens WJ, Lund VJ, Mullol J et al. European Position Paper on Rhinosinusitis and Nasal Polyps 2012. Rhinology Supplement. 2012(23):3 p preceding table of contents, 1-298.

2. Shah A, Ben-Shahar $Y$, Moninger T, Kline J, Welsh M. Motile cilia of human airway epithelia are chemosensory. Science. 2009;325:1131-4.

3. Lee R, Chen B, Redding K, Margolskee R, Cohen N. Mouse nasal epithelial innate immune responses to Pseudomonas aeruginosa quorum-sensing molecules require taste signaling components. Innate Immun. 2014;20:606-17.

4. Bachmanov A, Bosak N, Lin C, et al. Genetics of taste receptors. Curr Pharm Des. 2014;20(16):2669-83.

5. Lee R, Cohen N. Bitter and sweet taste receptors in the respiratory epithelium in health and disease. J Mol Med. 2014;92(12):1235-44.

6. Adappa N, Howland T, Palmer J et al. The bitter taste receptor T2R38 is an independent risk factor for chronic rhinosinusitis requiring sinus surgery. Int Forum Allergy Rhinol. 2014;4(1):3-7.

7. Adappa N, Howland T, Palmer J, et al. Genetics of the taste receptor T2R38 correlates with chronic rhinosinusitis necessitating surgical intervention. Int Forum Allergy Rhinol. 2013;3(3):184-7.

8. Lee R, Xiong G, Kofonow J, Chen B, Lysenko
A. T2R38 taste receptor polymorphisms underlie susceptibility to upper respiratory infection. J Clin Invest. 2012;122(11):414559.

9. Baguley C, Brownlow A, Yeung K, Pratt E, Sacks R, Harvey R. The fate of chronic rhinosinusitis sufferers after maximal medical therapy. Int Forum Allergy Rhinol. 2014;4(7):525-32.

10. Snidvongs K, Lam M, Sacks $R$ et al. Structured histopathology profiling of chronic rhinosinusitis in routine practice. Int Forum Allergy Rhinol. 2012;2(5):376-85.

11. Adappa N, Farquhar D, Palmer J et al. TAS2R38 genotype predicts surgical outcome in nonpolypoid chronic rhinosinusitis. Int Forum Allergy Rhinol. 2015;6(1):25-33. 
12. Dubin MG, Ebert CS, Coffey CS, Melroy CT, Sonnenburg RE, Senior BA. Concordance of middle meatal swab and maxillary sinus aspirate in acute and chronic sinusitis: a meta-analysis. Int Forum Allergy Rhinol. 2005; 19(5):462-70.

13. Rom D, Snidvongs $K$, Sacks PL et al. The impact of culturable bacterial community on histopathology in chronic rhinosinusitis. Int Forum Allergy Rhinol. 2014;4(1):29-33.

14. Ivanchenko OA, Karpishchenko SA, Kozlov RS et al. The microbiome of the maxillary sinus and middle nasal meatus in chronic rhinosinusitis. Rhinology. 2016;54(1):68-74.

15. Mantovani K, Rodrigues D, Tamashiro E et al. Comparing different methods used to collect material for a microbiological evaluation of patients with chronic rhinosinusitis.
Braz J Otorhinolaryngol. 2010;76(3):321-5.

16. Hsu J, Lanza D, Kennedy D. Antimicrobial resistance in bacterial chronic sinusitis. Int Forum Allergy Rhinol. 1998;12(4):243-8.

17. Stephenson M, Mfuna L, Dowd $S$ et al. Molecular characterization of the polymicrobial flora in chronic rhinosinusitis. J Otolaryngol Head Neck Surg. 2010;39(2):182-7.

18. Thanasumpun T, Batra PS. Endoscopicallyderived bacterial cultures in chronic rhinosinusitis: A systematic review. Am J Otolaryngol. 36(5):686-91.

19. Adappa ND, Truesdale CM, Workman AD et al. Correlation of T2R38 taste phenotype and in vitro biofilm formation from nonpolypoid chronic rhinosinusitis patients. Int Forum Allergy Rhinol. 2016;6(8):783-91.
Darren Rom

St Vincent's Centre for Applied

Medical Research

University of New South Wales

67 Burton St

Darlinghurst

Sydney

NSW, Australia 2010

Tel: +61 293604811

E-mail: drom4015@uni.sydney.edu.au 